\title{
Indicadores operacionais dos terminais de contêineres
}

Thiago de Almeida Rodrigues trodrigues.almeida@gmail.com Universidade Federal do Paraná (UFPR), Paranaguá, PR, Brasil

\section{Robson Seleme}

robsonseleme@ufpr.br

Universidade Federal do Paraná (UFPR), Curitiba, PR, Brasil

\author{
RESUMO
}

Os indicadores de desempenho são cruciais na gestão estratégica e dos processos de uma organização, podendo ser medido de diversas maneiras e em diferentes níveis de complexidades. Os terminais de contêineres, que são os responsáveis pela conexão entre os modais marítimo e terrestre, constituem um elemento central em qualquer sistema de transporte, considerando diversas variáveis operacionais a fim de obter melhores performances. Com isto, a pesquisa busca verificar na literatura se existe um conjunto de indicadores operacionais padrão para medir a eficiência dos terminais de contêineres. $O$ objetivo do artigo é determinar os indicadores operacionais mais relevantes dos terminais de contêineres, por meio de uma revisão sistemática realizada nas bases de dados Emerald, Scopus e Periódicos Capes, no período entre 2010 e 2016, apresentando os indicadores de referência. Como resultado da pesquisa, obteve-se um conjunto com 40 indicadores operacionais; estes podem ser utilizados como direcionadores para a gestão por indicadores com foco operacional em terminais de contêineres.
\end{abstract}

PALAVRAS-CHAVE: Indicadores. Terminal de contêiner. Operacional. 


\section{INTRODUÇÃO}

O transporte de carga geral em contêiner desempenha o papel mais importante na circulação de mercadorias no comércio internacional (SHAN, YU e LEE, 2014); (JIANG et al, 2015). Responsáveis pela conexão entre os modais marítimo e terrestre, os terminais de contêineres constituem um elemento central em qualquer sistema de transporte (TOVAR, HERNÁNDEZ e RODRÍGUEZDÉNIZ, 2015). A competitividade de um Porto está intimamente relacionada às decisões de seleção do porto pelos transportadores e, em geral, os portos que fornecem serviços mais confiáveis, eficientes e econômicos revelam-se mais atrativos (JIANG et al, 2015), (TALLEY e NG, 2013).

Com 8,5 mil quilômetros de costa navegável, o transporte marítimo no Brasil também cresce a cada ano, movimentando 931 milhões de toneladas de carga bruta em 2013, representando 90\% das exportações do país (PORTOS DO BRASIL, 2014). Com relação à movimentação de contêiner, o aumento é devido à eficiência operacional dos terminais especializados, que já realizaram investimentos de US\$ 2,8 bilhões em obras civis, aquisição de modernos equipamentos e especialização de mão de obra (ABRATEC, 2015).

Os Indicadores de desempenho são cruciais na gestão estratégica e dos processos de uma organização, podendo ocorrer em uma variedade de formas e complexidades. De forma geral, indicadores são índices para medir a grandeza de um processo fabril ou administrativo, para determinar se o mesmo está inserido nos parâmetros aceitáveis determinados pela companhia (MARTINS e LAUGENI, 2005). De acordo com Júnior (2008) os indicadores operacionais do setor portuário permitem qualificar os serviços em cada porto, além de fazer comparações evolutivas de desempenho dos terminais, possibilitando monitorar a evolução do processo com o estabelecimento de benchmark. A utilização de indicadores possibilita aos clientes buscarem os terminais que melhor atendam suas exigências, favorecendo a competitividade entre os terminais e demonstrando o resultado do setor no âmbito nacional.

Contudo, entre os diversos indicadores operacionais existentes, quais são os de maior importância para um terminal de contêineres? Quais devem ser tratados como prioridade? Com base neste contexto, o problema de pesquisa é: Existe um conjunto de indicadores operacionais padrão para medir a eficiência operacional dos terminais de contêineres?

O objetivo do artigo é determinar os indicadores operacionais mais relevantes dos terminais de contêineres, por meio de uma revisão sistemática, oferecendo assim um conjunto de indicadores como referência. Para tal, faz-se necessário desenvolver os objetivos específicos, que são: estruturação das etapas da revisão sistemática, realização da revisão sistemática, levantamento e consolidação dos indicadores operacionais dos terminais de contêineres.

\section{REFERENCIAL TEÓRICO}

Métricas encorajam os gestores e funcionários a tomarem as decisões e ações que eles acreditam serem as melhores para alcançar a meta. Se as métricas forem escolhidas com cuidado, gerentes e colaboradores irão tomar as decisões certas que possibilitarão à empresa maximizar o seu lucro em longo prazo 
(HAUSER e KATZ, 1998). Contudo, muitos executivos que procuram criar valor aos acionistas também confiam na própria intuição na escolha dos indicadores, o que pode levar a escolhas ruins (MAUBOUSSIN, 2012).

Geralmente as empresas adicionam novas formas de mensurar considerando até sugestões dos colaboradores; em contrapartida, o Balanced Scorecard (BSC) foca no que realmente é importante para a companhia, o que é mais crítico. (KAPLAN e NORTON, 1992).

Nesse contexto, alinhando a estratégia e os objetivos da empresa com seus indicadores, o BSC, com um olhar em longo prazo, ajuda a companhia a se concentrar nos pontos focais, o que remete ao problema da pesquisa, buscando identificar os principais indicadores operacionais dos terminais de contêineres. Muitas empresas acompanham mais indicadores do que elas podem utilizar, porém o BSC exige que os gestores cheguem a um acordo sobre as medidas que são mais críticas para o sucesso da estratégia da empresa (KAPLAN e NORTON, 1993).

As empresas devem utilizar sistemas de medição de desempenho a fim de obter sucesso na competição do mercado. Isto posto, estes indicadores devem ser desenvolvidos de acordo com as estratégias da empresa e com o modelo de gestão, sendo efetuadas de forma sistêmica (NIEDRITIS, NIEDRITE, KOZMINA, 2011). O mesmo autor afirma que experiências do mundo real mostram que as empresas usam medidas erradas, muitas das quais são incorretamente tratadas como indicadores-chave de desempenho.

\section{INDICADORES OPERACIONAIS DOS TERMINAIS DE CONTÊINERES}

A proporção de carga transportada em contêineres aumentou de 3\% em 1980 para 16\% em 2011 (RIOS e SOUZA, 2014). Logo, a eficiência do porto é um importante indicador de desempenho; portos mais eficientes reduzem os custos de transporte e facilitam as importações e exportações de um país. Apesar da importância do tema, os estudos de eficiência portuária existentes têm-se centrado quase exclusivamente em terminais de contêineres (MERK e DANG, 2012).

Comumente a análise de terminais de contêineres é baseada na avaliação e comparação de parâmetros quantitativos que descrevem o nível de serviço do terminal e por meio de indicadores de desempenho relacionados com a produtividade do terminal (CAGGIANI et al, 2012). Como cada terminal possui sua própria estratégia de negócio, estes não podem ser avaliados com base em um único indicador.

As principais operações no porto começam com a chegada de um navio; após atracado, inicia-se uma série de atividades para realizar a carga ou descarga do mesmo. Essas atividades podem ser representadas por indicadores como o área de armazenamento (tamanho do pátio), quantidade de berços (locais para atracação do navio) e portêineres (guindastes para operação de contêineres no navio), tempo que o caminhão externo permaneceu no terminal, produtividade e capacidade dos equipamentos, taxa terno (quantidade de portêineres utilizados para operar um navio), janela de atracação, proximidade do berço com o pátio de alocação dos contêineres, tempo de operação do navio, custo médio operacional por navio, custo do contêiner no pátio, tempo de permanência do contêiner no 
terminal, quantidade de caminhões utilizados no transporte dos contêineres, tempo médio do percurso da rota de carga e descarga do caminhão, quantidade de viagens por veículo, utilização do portão de entrada (gate), entre outros (RASHIDI e TSANG, 2013).

Entre os indicadores citados por Merk e Dang (2012) encontram-se o volume de toneladas bruto e o número de TEUs (Twenty Foot Equivalent Unit) movimentados. Além destes, diversas variáveis de entrada são identificadas como, o capital investido na infraestrutura do terminal, o comprimento do cais, o número de tomadas reefer, a capacidade de armazenamento e a quantidade de portêineres e transtêineres (guindaste sob trilhos para operação de contêineres no pátio).

No trabalho de Cartenì e Luca (2012), diferentes modelos de simulação de eventos discretos são apresentados para um terminal de contêineres. Para tal, os autores apresentam diversos indicadores de desempenho como o tempo de duração de cada atividade, o tempo de empilhamento, carregamento e descarregamento dos contêineres, o tempo de transporte da carga até o portêiner, tempo de atracação do navio, demanda de movimentação, velocidade de operação dos equipamentos e tempo de operação do terminal.

Os terminais de contêineres dependem principalmente dos tipos de equipamentos que são manuseados de forma combinada para formar o sistema do terminal. As atividades de logística, especialmente em terminais de contêineres de grande porte, tem atingido um grau de complexidade que se faz necessário novas melhorias para proporcionar a interação deste sistema complexo. Com isso, outros indicadores também são levantados por Nooramin, Ahouei e Sayereh (2011), a utilização do espaço físico e dos equipamentos, considerando também o tempo gasto para o carregamento/descarregamento das cargas dos caminhões.

A função do porto tem evoluído de uma plataforma de prestação de atividades de carga e descarga simples para uma porta de entrada para inúmeras oportunidades logísticas, que resultam em benefícios econômicos. Neste contexto, a pesquisa de Loh e Thai (2014) apresenta perspectivas da indústria com relação às interrupções na cadeia de suprimentos relacionadas aos portos, identificando a quebra de equipamentos, utilização de equipamentos inadequados para a movimentação de carga e descarga e a escassez de mão de obra resulta em interrupções na cadeia logística. Entre os demais temas levantados, encontram-se a necessidade de integração entre os modais dos portos, a capacidade para receber navios maiores, a eficiência dos equipamentos, o layout do pátio de armazenamento e o suporte de hardware, resultando assim em maior valor agregado aos clientes.

Sendo um ponto chave em uma rede de transportes, o tempo de trânsito de contêineres por um terminal representa um dos gargalos relevantes em cadeias logísticas. A redução do desempenho operacional do sistema e o correspondente aumento do tempo de trânsito são muitas vezes devido ao aumento do fluxo de mercadorias, sem um aumento correspondente da capacidade de movimentação. Com isso, Baldassara, Impastato e Ricci (2010) abordaram este problema com um modelo de simulação de eventos discretos, a fim de reproduzir as atividades realizadas dentro de um terminal intermodal, para calcular o tempo de trânsito total e para identificar os gargalos. Entre os indicadores utilizados estão a 
intermodalidade do terminal, o tempo de trânsito da carga e o tempo de carga e descarga dos contêineres no navio.

O crescimento do transporte de mercadorias em contêineres tem criado muitos desafios para os terminais, que precisam melhorar sua produtividade e infraestrutura para receber navios cada vez maiores. Para enfrentar esses desafios, os terminais têm de inovar e, muitas vezes automatizar equipamentos para aperfeiçoar seus processos logísticos (RASHIDI e TSANG, 2013). No entanto, atualmente não existem indicadores padronizados para poder medir o grau de especialização e eficiência das atividades realizadas.

\section{METODOLOGIA}

Para realizar uma investigação da literatura de um assunto específico, tornase necessário seguir uma estrutura de trabalho rígida. A utilização da revisão sistemática permite ao pesquisador mapear e avaliar o estado da arte disponível a fim de tornar o conteúdo encontrado mais consistente e aderente à questão de pesquisa (TRANFIELD, DEYER e SMART, 2003). De forma geral, a revisão sistemática segue as atividades de delimitação do tema, das palavras-chave, do período de pesquisa e da base de dados, classificando os resultados de acordo com o procedimento desenvolvido por Gohr et al. (2013) e Tranfield, Denyer e Smart (2003). A Figura 1 apresenta as etapas da revisão sistemática das publicações nas bases de dados juntamente com a busca por indicadores nos órgãos, instituições e associações dos terminais de contêineres.

\section{DEFINIÇÃO DA PERGUNTA DE PESQUISA}

A pergunta de pesquisa, como descrito anteriormente é: Quais são os indicadores operacionais mais relevantes para os terminais de contêineres?

\section{DEFINIÇÃO DO FOCO}

O foco da revisão sistemática é a identificação dos indicadores operacionais específicos dos terminais de contêineres. Demais indicadores não serão considerados nesta pesquisa. 
Figura 1 - Processo de revisão sistemática

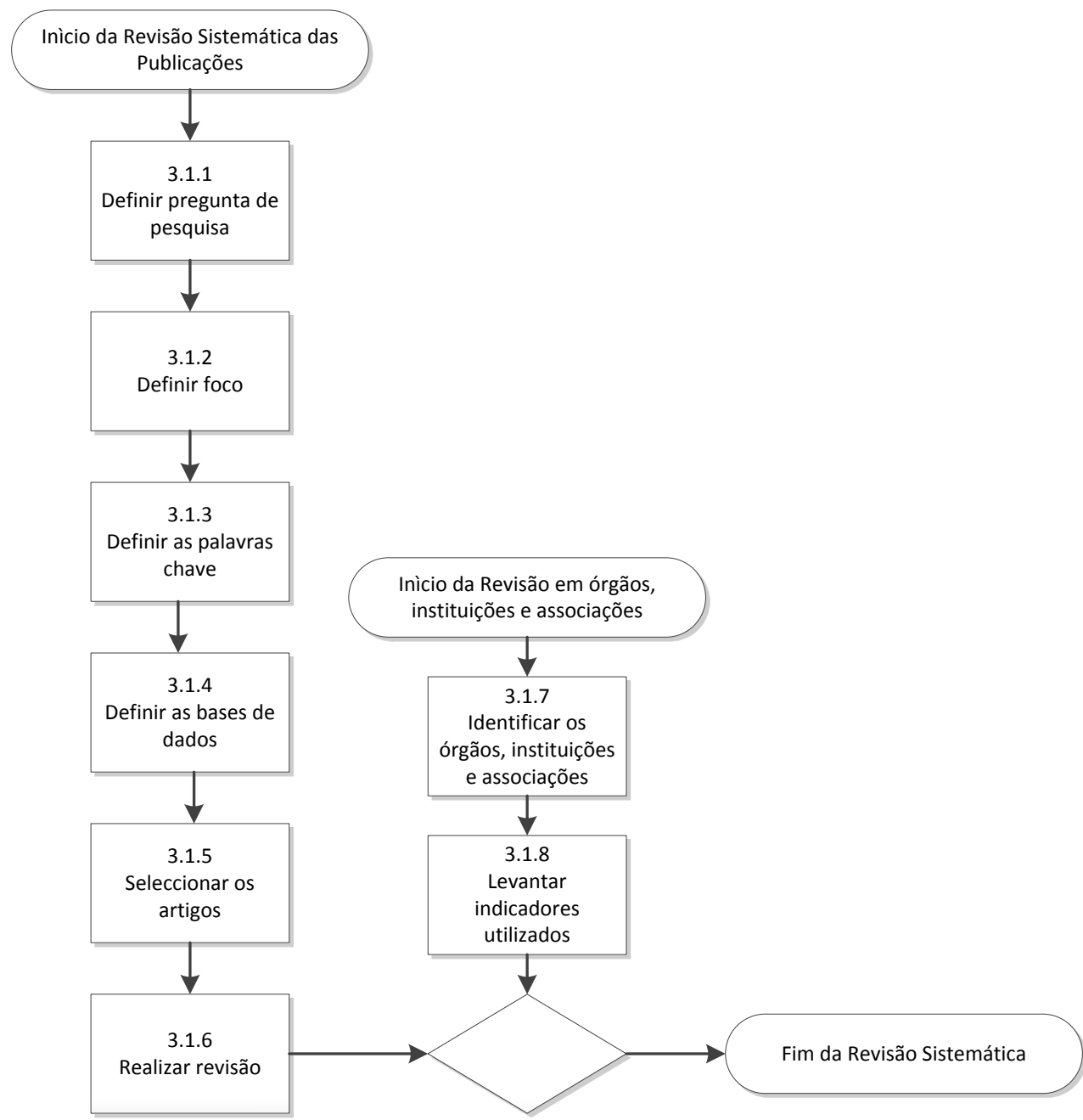

Fonte: Baseado em Gohr et al. (2013) e Tranfield, Denyer e Smart (2003).

\section{DEFINIÇÃO DAS PALAVRAS-CHAVE}

As palavras-chave pesquisadas nas bases de dados foram: container port e container terminal, relacionados às palavras-chave performance indicator e operational indicator.

\section{DEFINIÇÃO DAS BASES DE DADOS}

As bases de dados selecionadas para realização da revisão sistemática foram Scopus, Periódicos Capes e Emerald Insights. Com 55 milhões de registros, 21.915 títulos e 5.000 editores, a Scopus é a maior base de dados de resumos e citações de literatura revisada por pares, possuindo revistas científicas, livros e anais de 
congressos, oferecendo uma visão abrangente das pesquisas do mundo em diversas áreas (SCOPUS, 2015). Já o Periódicos Capes é uma biblioteca virtual que conta atualmente com um acervo de mais de 37 mil periódicos com textos completos, 126 bases referenciais, 11 bases dedicadas exclusivamente a patentes, além de livros, enciclopédias e obras de referência, normas técnicas, estatísticas e conteúdo audiovisual (PERIÓDICOS CAPES, 2015). Por fim, a Emerald é uma editora global que associa a investigação e prática para o benefício da sociedade. A empresa administra um portfólio de mais de 295 revistas e mais de 2.500 livros (EMERALD, 2015).

Por meio destas informações, confirma-se que as bases de dados selecionadas estão relacionadas ao tema em questão e garantem a confiabilidade e qualidade das informações.

\section{SELEÇÃO DOS ARTIGOS}

Por meio da busca nas bases de dados com as palavras-chave supracitadas, restringindo-se o ano de publicação entre 2010 e 2016, obteve-se como resultado 51 publicações na base Scopus, 1747 publicações na Emerald Insights e 188 no Periódicos Capes. Nesta busca, não foram utilizados filtros em tipos de publicações, buscando assim, maior abrangência na pesquisa.

\section{REALIZAÇÃO DA REVISÃO}

A primeira revisão realizou-se com o objetivo de eliminar os artigos repetidos; como resultado obteve-se 29 artigos na base Scopus, 1207 na Emerald Insight e 134 no Periódicos Capes. Posteriormente realizou-se a segunda revisão, analisando o título das publicações, buscando aqueles que estivessem alinhadas ao objetivo definido; como resultado da segunda revisão obteve-se 16 publicações na base Scopus, 18 na Emerald Insight e 11 no Periódicos Capes. Por fim, na terceira revisão realizou-se uma leitura do resumo do artigo, verificando se o mesmo era compatível à proposta da pesquisa; após esta revisão, foram selecionadas 17 publicações, 6 da base Scopus, 6 da Emerald Insight e 5 do Periódicos Capes, compondo assim a base teórica com os indicadores operacionais dos terminais de contêiner utilizados nesta pesquisa. Um resumo do quantitativo de artigos por revisão e por base de dados segue no Gráfico 1.

Gráfico 1 - Seleção dos artigos por meio da revisão sistemática

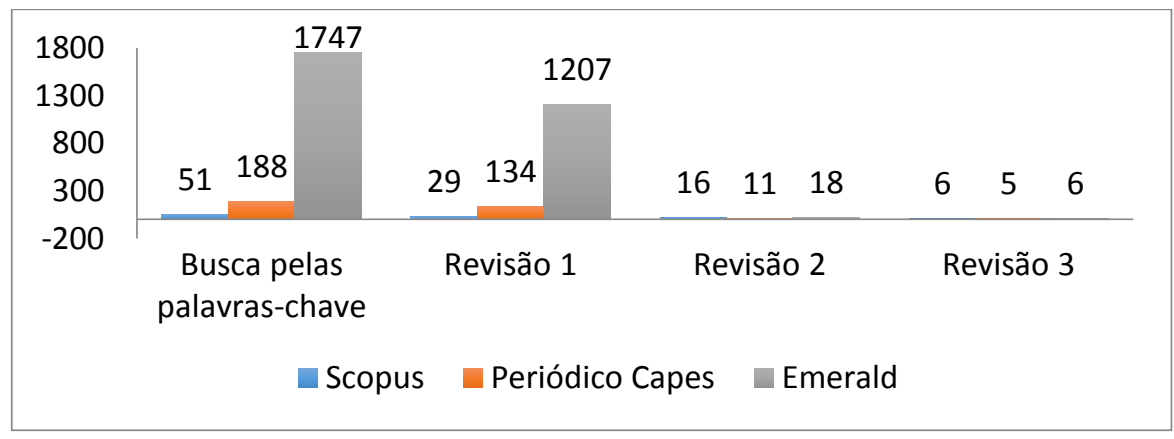

Fonte: Elaboração própria (2015). 


\section{IDENTIFICAÇÃO DOS ÓRGÃOS, INSTITUIÇÕES E ASSOCIAÇÕES DOS TERMINAIS DE CONTÊINERES}

Após realizar uma busca entre os sites de organizações governamentais e de terminais de contêineres especificamente, identificou-se as instituições que seguem na Tabela 1. Em seus respectivos sites, constam relatórios, anuários e estatísticas que consideram indicadores operacionais de terminais de contêineres, sendo relevante para a realização desta pesquisa.

Tabela 1 - Instituições referentes aos terminais de contêineres

\begin{tabular}{|c|c|c|}
\hline Órgão, Associação, Instituição & Sigla & O que é? \\
\hline $\begin{array}{l}\text { American Association of Port } \\
\text { Authorities }\end{array}$ & AAPA & $\begin{array}{l}\text { É uma associação que representa mais de } \\
130 \text { autoridades portuárias públicas nos } \\
\text { Estados Unidos, Canadá, Caribe e América } \\
\text { Latina. }\end{array}$ \\
\hline $\begin{array}{l}\text { Associação Brasileira dos } \\
\text { Terminais de Contêineres de Uso } \\
\text { Público }\end{array}$ & ABRATEC & $\begin{array}{l}\text { Associação que representa, em âmbito } \\
\text { nacional, as empresas arrendatárias de } \\
\text { terminais portuários de uso público, } \\
\text { especializados na movimentação de } \\
\text { contêineres. }\end{array}$ \\
\hline $\begin{array}{l}\text { Agência Nacional de Transportes } \\
\text { Aquaviários }\end{array}$ & ANTAQ & $\begin{array}{l}\text { Entidade que integra a Administração } \\
\text { Federal indireta, de regime autárquico } \\
\text { especial, que é responsável por regular, } \\
\text { supervisionar e fiscalizar as atividades de } \\
\text { prestação de serviços de transporte } \\
\text { aquaviário e de exploração da } \\
\text { infraestrutura portuária e aquaviária }\end{array}$ \\
\hline $\begin{array}{l}\text { International Association of Ports } \\
\text { and Harbors }\end{array}$ & $\mathrm{IAPH}$ & $\begin{array}{l}\text { Reconhecida como a única organização } \\
\text { internacional que representa a voz da } \\
\text { indústria portuária do mundo, a IAPH é } \\
\text { uma Organização Não Governamental } \\
\text { (ONG) de cinco Nações, sendo uma } \\
\text { agência especializada e um organismo } \\
\text { intergovernamental. }\end{array}$ \\
\hline $\begin{array}{l}\text { United Nations Conference on } \\
\text { Trade and Development }\end{array}$ & UNCTAD & $\begin{array}{l}\text { Regida pelos seus } 194 \text { Estados-membros, } \\
\text { a UNCTAD é um órgão das Nações Unidas } \\
\text { responsável por lidar com questões de } \\
\text { desenvolvimento, } \\
\text { internacional. }\end{array}$ \\
\hline
\end{tabular}

Fonte: Elaboração própria (2015).

\section{LEVANTAMENTO DOS INDICADORES UTILIZADOS}

Com base nos artigos selecionados e nos relatórios e estatísticas das instituições apresentadas anteriormente, possibilita-se identificar os indicadores operacionais dos terminais de contêineres. Nos resultados serão especificados os autores de cada trabalho e os indicadores abordados pelos mesmos; após uma revisão, será apresentado um quadro com os 40 indicadores resultantes da pesquisa, com a explicação do seu objetivo e justificativa de ser mensurado. 


\section{RESULTADOS E DISCUSSÃO}

Como resultado da revisão sistemática, foram selecionados 17 artigos após a terceira revisão realizada. Desses 17 artigos, 14 deles estão definidos no Quadro 1 , especificando os autores e os indicadores mencionados em suas pesquisas.

Quadro 1 - Indicadores operacionais dos terminais de contêineres

\begin{tabular}{|c|c|}
\hline Artigo & Indicadores Operacionais \\
\hline \multirow{7}{*}{ Huang et al. (2010) } & Custos das instalações portuárias \\
\hline & Custos da operação \\
\hline & Custos dos equipamentos \\
\hline & Custos de manutenção \\
\hline & Custos da mão-de-obra \\
\hline & Custos de estocagem de carga \\
\hline & Movimentação dos guindastes \\
\hline \multirow{3}{*}{$\begin{array}{c}\text { Baldassara, } \\
\text { Impastato e Ricci } \\
\text { (2010) }\end{array}$} & Intermodalidade do terminal \\
\hline & Tempo de trânsito da carga \\
\hline & Tempo da operação de carga e descarga \\
\hline \multirow{5}{*}{ Pun e Nurse (2010) } & Manutenção dos equipamentos \\
\hline & Custos de manutenção \\
\hline & Produtividade do navio \\
\hline & Produtividade do berço \\
\hline & Tempo de rotação dos caminhões no terminal \\
\hline \multirow{3}{*}{$\begin{array}{c}\text { Al-Eraqi, Mustafa e } \\
\text { Khader (2010) }\end{array}$} & Comprimento do cais \\
\hline & Área total do porto \\
\hline & Total de toneladas movimentadas \\
\hline \multirow{12}{*}{$\begin{array}{c}\text { Yeo, Roe e } \\
\text { Dinwoodie (2011) }\end{array}$} & Disponibilidade do berço de atracação \\
\hline & Quantidade de carga movimentada \\
\hline & Custo da movimentação de carga \\
\hline & Capacidade de armazenamento \\
\hline & Equipamentos de transporte \\
\hline & Tempo de permanência gratuito da carga no terminal \\
\hline & Frequência de perdas e danos à carga \\
\hline & Custos de transporte interno \\
\hline & Intermodalidade do terminal \\
\hline & Quantidade de mão de obra especializada na operação \\
\hline & Produtividade do terminal \\
\hline & Volume de contêineres movimentados \\
\hline
\end{tabular}




\begin{tabular}{|c|c|}
\hline & Calado do cais \\
\hline & Tempo de espera de atracação \\
\hline \multirow{12}{*}{$\begin{array}{l}\text { Feng, Mangan e } \\
\text { Lalwani (2011) }\end{array}$} & Taxa de transferência de volume em contêiner \\
\hline & Área do terminal \\
\hline & Instalações portuárias \\
\hline & Tempo médio de espera do navio no porto \\
\hline & Disponibilidade dos equipamentos \\
\hline & Tempo da operação de carregamento \\
\hline & Quantidade de horas de retenção \\
\hline & Manutenção dos equipamentos \\
\hline & Profundidade do cais \\
\hline & Comprimento do cais \\
\hline & Quantidade de portêineres e transtêineres \\
\hline & Intermodalidade do terminal \\
\hline \multirow{5}{*}{$\begin{array}{c}\text { Nooramin, Ahouei e } \\
\text { Sayareh (2011) }\end{array}$} & Tempo de espera dos caminhões na fila do terminal \\
\hline & Produtividade do terminal \\
\hline & Utilização dos equipamentos \\
\hline & Ocupação do pátio \\
\hline & Tempo para carga e descarga dos caminhões \\
\hline \multirow{11}{*}{ Cartenì e Luca (2012) } & Tempo de duração da operação \\
\hline & Tempo de empilhamento dos contêineres no navio \\
\hline & Tempo da operação de carga e descarga \\
\hline & Produtividade do portêiner \\
\hline & Tempo de transporte da carga até o portêiner \\
\hline & Tempo que o navio ficou atracado \\
\hline & Produtividade do transtêiner \\
\hline & Tempo de movimentação do contêiner pelo caminhão \\
\hline & Demanda de movimentação \\
\hline & Velocidade de operação dos equipamentos \\
\hline & Tempo de operação do terminal \\
\hline \multirow{6}{*}{ Caggiani et al. (2012) } & Produtividade do terminal \\
\hline & Taxa de utilização dos equipamentos \\
\hline & Custos operacionais \\
\hline & Calado do cais \\
\hline & Comprimento do cais \\
\hline & Área do pátio de armazenagem \\
\hline
\end{tabular}




\begin{tabular}{|c|c|}
\hline & Quantidade de equipamentos \\
\hline $\begin{array}{l}\text { Largen e Sharypova } \\
\qquad(2013)\end{array}$ & Conectividade intermodal \\
\hline \multirow{24}{*}{$\begin{array}{l}\text { Rashidi e Tsang } \\
\qquad \text { (2013) }\end{array}$} & Área do pátio de armazenagem \\
\hline & Quantidade de berços \\
\hline & Quantidade de equipamentos \\
\hline & Tempo que o caminhão externo permanece no terminal \\
\hline & Produtividade por portêiner \\
\hline & Taxa terno \\
\hline & Tempo da janela de atracação \\
\hline & Proximidade entre o berço e o bloco de carga no pátio \\
\hline & Capacidade dos equipamentos \\
\hline & Tempo de operação do navio \\
\hline & Tempo ocioso do portêiner \\
\hline & Tempo de espera por carga pelo portêiner \\
\hline & Custo médio operacional por navio \\
\hline & Tamanho dos blocos no pátio \\
\hline & Custo do contêiner no pátio \\
\hline & Tempo de permanência do contêiner no terminal \\
\hline & Quantidade de movimentos realizados pelo transtêiner \\
\hline & Tempo de retorno dos caminhões para carregar \\
\hline & Custo médio de transporte por contêiner \\
\hline & Quantidade de veículos utilizados \\
\hline & Ociosidade dos veículos \\
\hline & Tempo médio do percurso de carga e descarga do caminhão \\
\hline & Quantidade de viagens por veículo \\
\hline & Utilização do portão de entrada (gate) \\
\hline \multirow{6}{*}{ Lam e Song (2013) } & Eficácia da operação \\
\hline & Confiabilidade da operação \\
\hline & Agilidade da operação \\
\hline & Tempo de resposta da operação \\
\hline & Tempo de carga em trânsito \\
\hline & Custos operacionais \\
\hline \multirow{3}{*}{ Tapia et al. (2014) } & Eficiência dos recursos de movimentação \\
\hline & Tempo de utilização dos equipamentos \\
\hline & Custos de Homem/hora \\
\hline
\end{tabular}




\begin{tabular}{|c|c|}
\hline \multirow{1}{*}{ Rios e Souza (2014) } & Movimentos por hora do portêiner \\
\cline { 2 - 3 } & Quantidade de contêineres movimentados \\
\cline { 2 - 3 } & Comprimento do cais \\
\cline { 2 - 3 } & Cúmero de berços de atracação \\
\cline { 2 - 3 } & Calado do cais \\
\cline { 2 - 3 } & Produtividade das operações \\
\cline { 2 - 3 } & Tempo médio de espera por atracação \\
\cline { 2 - 3 } & Tempo médio de operação \\
\cline { 2 - 3 } & Tamanho dos navios atracados \\
\cline { 2 - 3 } & Tamanho do pátio de armazenamento \\
\hline
\end{tabular}

Fonte: Elaboração própria (2015).

Muitos dos artigos mencionados apresentam indicadores semelhantes. Por fim, realizou-se outra revisão entre os indicadores do Quadro 1, eliminando-se as repetições. O resultado apresenta-se no Quadro 2, com o consolidado de 40 indicadores operacionais, descrevendo o objetivo e a justificativa por utilizar tal indicador.

Quadro 2 - Síntese dos indicadores operacionais

\begin{tabular}{|c|c|c|}
\hline Indicadores & Objetivo & Justificativa \\
\hline $\begin{array}{l}\text { Alcance dos } \\
\text { Portêineres }\end{array}$ & $\begin{array}{l}\text { Identificar se o portêiner pode } \\
\text { trabalhar com navios maiores }\end{array}$ & $\begin{array}{l}\text { O aumento da capacidade e do } \\
\text { tamanho dos navios porta- } \\
\text { contêineres }\end{array}$ \\
\hline Calado do cais & $\begin{array}{l}\text { Determinar a profundidade do } \\
\text { cais de atracação }\end{array}$ & $\begin{array}{l}\text { Dado o aumento no tamanho dos } \\
\text { navios porta-contêineres, fazem- } \\
\text { se necessários portos com } \\
\text { calados maiores }\end{array}$ \\
\hline $\begin{array}{l}\text { Capacidade dos } \\
\text { equipamentos }\end{array}$ & $\begin{array}{l}\text { Determinar a capacidade do } \\
\text { equipamento segundo sua } \\
\text { unidade de medida específica }\end{array}$ & $\begin{array}{l}\text { Identificar se os equipamentos } \\
\text { disponíveis são adequados para } \\
\text { realizarem determinada } \\
\text { atividade }\end{array}$ \\
\hline $\begin{array}{l}\text { Capital investido } \\
\text { em } \\
\text { infraestrutura }\end{array}$ & $\begin{array}{c}\text { Mensurar o capital investido em } \\
\text { infraestrutura }\end{array}$ & $\begin{array}{l}\text { Obter uma visão holística se os } \\
\text { equipamentos e infraestrutura } \\
\text { do terminal são modernos }\end{array}$ \\
\hline $\begin{array}{c}\text { Comprimento } \\
\text { do cais }\end{array}$ & $\begin{array}{c}\text { Identificar a quantidade de navios } \\
\text { que podem atracar ao mesmo } \\
\text { tempo }\end{array}$ & $\begin{array}{c}\text { Aumento do fluxo de navios } \\
\text { porta-contêineres }\end{array}$ \\
\hline
\end{tabular}




\begin{tabular}{|c|c|c|}
\hline $\begin{array}{l}\text { Conectividade } \\
\text { intermodal }\end{array}$ & $\begin{array}{c}\text { Identificar com quais modais o } \\
\text { terminal de contêineres está } \\
\text { conectado }\end{array}$ & $\begin{array}{l}\text { Diferencial logístico que reduz } \\
\text { custos e auxilia em uma maior } \\
\text { ramificação do terminal }\end{array}$ \\
\hline $\begin{array}{l}\text { Confiabilidade } \\
\text { da operação }\end{array}$ & $\begin{array}{l}\text { Identificar se a operação será } \\
\text { realizada por completo }\end{array}$ & $\begin{array}{l}\text { Atender às determinações dos } \\
\text { clientes e cumprimento de } \\
\text { janelas de atracação }\end{array}$ \\
\hline $\begin{array}{l}\text { Custo da mão- } \\
\text { de-obra }\end{array}$ & $\begin{array}{c}\text { Mensurar o custo da mão de obra } \\
\text { utilizado nas operações }\end{array}$ & Controlar e reduzir custos \\
\hline $\begin{array}{l}\text { Custo da } \\
\text { operação }\end{array}$ & $\begin{array}{l}\text { Identificar o custo na realização } \\
\text { de alguma atividade operacional }\end{array}$ & $\begin{array}{c}\text { Identificar perdas, reduzir custos } \\
\text { e otimizar recursos }\end{array}$ \\
\hline $\begin{array}{l}\text { Custos de } \\
\text { manutenção }\end{array}$ & $\begin{array}{c}\text { Mensurar e controlar os custos } \\
\text { com manutenção }\end{array}$ & Controlar e reduzir custos \\
\hline $\begin{array}{l}\text { Demanda de } \\
\text { movimentação }\end{array}$ & $\begin{array}{l}\text { Determinar a variação do volume } \\
\text { de carga trabalhado no terminal }\end{array}$ & $\begin{array}{l}\text { Avaliar níveis comerciais do } \\
\text { terminal e capacidade de } \\
\text { atendimento operacional }\end{array}$ \\
\hline $\begin{array}{l}\text { Disponibilidade } \\
\qquad \text { dos } \\
\text { equipamentos }\end{array}$ & $\begin{array}{l}\text { Identificar se o equipamento está } \\
\text { disponível no momento em que } \\
\text { for requisitado }\end{array}$ & Gerar ações de manutenção \\
\hline $\begin{array}{l}\text { Frequência de } \\
\text { perdas e danos } \\
\text { à carga }\end{array}$ & $\begin{array}{c}\text { Identificar e controlar a } \\
\text { ocorrência de perdas e avarías na } \\
\text { carga }\end{array}$ & Atender os requisitos do cliente \\
\hline $\begin{array}{l}\text { Confiabilidade } \\
\qquad \text { dos } \\
\text { equipamentos }\end{array}$ & $\begin{array}{l}\text { Mensurar a quantidade de } \\
\text { quebras durante a operação }\end{array}$ & Gerar ações de manutenção \\
\hline $\begin{array}{l}\text { Número de } \\
\text { berços }\end{array}$ & $\begin{array}{c}\text { Determinar quantos navios } \\
\text { podem atracar ao mesmo tempo }\end{array}$ & $\begin{array}{l}\text { Aumento do fluxo de navios } \\
\text { porta-contêineres }\end{array}$ \\
\hline $\begin{array}{l}\text { Número de } \\
\text { tomadas reefer }\end{array}$ & $\begin{array}{l}\text { Determinar quantos contêineres } \\
\text { reefer podem ser armazenados no } \\
\text { terminal }\end{array}$ & $\begin{array}{l}\text { A armazenagem e transporte do } \\
\text { contêiner reefer resultam em } \\
\text { ganhos financeiros ao terminal }\end{array}$ \\
\hline $\begin{array}{l}\text { Ocupação do } \\
\text { pátio }\end{array}$ & $\begin{array}{l}\text { Determinar a porcentagem de } \\
\text { área ocupada no pátio }\end{array}$ & $\begin{array}{l}\text { Possibilita verificar o fluxo de } \\
\text { carga do terminal e sua } \\
\text { capacidade }\end{array}$ \\
\hline $\begin{array}{l}\text { Produtividade } \\
\text { do berço de } \\
\text { atracação }\end{array}$ & $\begin{array}{c}\text { Mensurar quantos navios atracam } \\
\text { em determinado berço }\end{array}$ & $\begin{array}{c}\text { Avaliar a frequência de atracação } \\
\text { no berço }\end{array}$ \\
\hline $\begin{array}{l}\text { Produtividade } \\
\text { dos }\end{array}$ & $\begin{array}{c}\text { Mensurar o desempenho dos } \\
\text { equipamentos }\end{array}$ & $\begin{array}{l}\text { Possibilita agir sobre os } \\
\text { equipamentos com baixa }\end{array}$ \\
\hline
\end{tabular}




\begin{tabular}{|c|c|c|}
\hline equipamentos & & produtividade \\
\hline $\begin{array}{c}\text { Proximidade } \\
\text { entre o berço e } \\
\text { o bloco de carga } \\
\text { no pátio }\end{array}$ & $\begin{array}{c}\text { Mensurar a distância percorrida } \\
\text { pelos caminhões }\end{array}$ & $\begin{array}{c}\text { Buscar reduzir esta distância, } \\
\text { aumentando assim a velocidade } \\
\text { do transporte do contêiner }\end{array}$ \\
\hline $\begin{array}{l}\text { Quantidade de } \\
\text { equipamentos }\end{array}$ & $\begin{array}{l}\text { Identificar a quantidade de } \\
\text { equipamentos assim como o tipo } \\
\text { de equipamento }\end{array}$ & $\begin{array}{l}\text { Verificar se o terminal possui } \\
\text { equipamentos necessários para } \\
\text { realizar a operação }\end{array}$ \\
\hline $\begin{array}{l}\text { Quantidade de } \\
\text { movimentos } \\
\text { realizados pelos } \\
\text { equipamentos }\end{array}$ & $\begin{array}{l}\text { Verificar quais equipamentos } \\
\text { performam melhor e/ou estão } \\
\text { sendo mais utilizados }\end{array}$ & $\begin{array}{c}\text { Programar as manutenções } \\
\text { preventivas }\end{array}$ \\
\hline $\begin{array}{l}\text { Quantidade de } \\
\text { Portêineres e } \\
\text { transtêineres }\end{array}$ & $\begin{array}{l}\text { Identificar a quantidade destes } \\
\text { que são os equipamentos de carga } \\
\text { e descarga de contêineres mais } \\
\text { relevantes }\end{array}$ & $\begin{array}{l}\text { Por serem os equipamentos mais } \\
\text { relevantes, impactam } \\
\text { diretamente no desempenho do } \\
\text { terminal }\end{array}$ \\
\hline $\begin{array}{l}\text { Quantidade de } \\
\text { veículos } \\
\text { utilizados }\end{array}$ & $\begin{array}{l}\text { Mensurar a quantidade de } \\
\text { recursos de transporte }\end{array}$ & $\begin{array}{c}\text { Possibilita identificar a } \\
\text { velocidade com que a carga pode } \\
\text { ser transportada pelo terminal }\end{array}$ \\
\hline $\begin{array}{l}\text { Quantidade de } \\
\text { viagens por } \\
\text { veículo }\end{array}$ & Identificar a utilização do veículo & Gerar ações de manutenção \\
\hline $\begin{array}{c}\text { Quebra de } \\
\text { equipamentos }\end{array}$ & $\begin{array}{l}\text { Mensurar a quantidade de } \\
\text { quebras durante a operação }\end{array}$ & Gerar ações de manutenção \\
\hline $\begin{array}{c}\text { Tamanho do } \\
\text { pátio de } \\
\text { armazenamento }\end{array}$ & $\begin{array}{l}\text { Mensurar a capacidade de } \\
\text { armazenamento }\end{array}$ & $\begin{array}{c}\text { Identificar espaço ocioso ou } \\
\text { capacidade para realizar novos } \\
\text { negócios }\end{array}$ \\
\hline $\begin{array}{c}\text { Taxa de } \\
\text { utilização dos } \\
\text { equipamentos }\end{array}$ & $\begin{array}{c}\text { Mensurar quais equipamentos são } \\
\text { mais utilizados }\end{array}$ & Gerar ações de manutenção \\
\hline Taxa terno & $\begin{array}{l}\text { Quantidade de Portêineres que } \\
\text { podem trabalhar no navio }\end{array}$ & $\begin{array}{c}\text { Estimar a produtividade em que } \\
\text { se pode trabalhar o navio }\end{array}$ \\
\hline $\begin{array}{c}\text { Tempo de } \\
\text { espera dos } \\
\text { caminhões na } \\
\text { fila do terminal }\end{array}$ & $\begin{array}{l}\text { Mensurar a fila de entrada de } \\
\text { caminhões e o fluxo no terminal }\end{array}$ & $\begin{array}{l}\text { Possibilita identificar o tamanho } \\
\text { da fila e o tempo de operação do } \\
\text { gate }\end{array}$ \\
\hline
\end{tabular}




\begin{tabular}{|c|c|c|}
\hline $\begin{array}{l}\text { Tempo de } \\
\text { permanência do } \\
\text { contêiner no } \\
\text { terminal }\end{array}$ & $\begin{array}{l}\text { Mensurar o tempo desde que o } \\
\text { contêiner foi desembarcado do } \\
\text { navio até ser retirado do terminal }\end{array}$ & $\begin{array}{c}\text { Este tempo impacta na ocupação } \\
\text { do terminal }\end{array}$ \\
\hline $\begin{array}{c}\text { Tempo de } \\
\text { permanência } \\
\text { gratuito da } \\
\text { carga no } \\
\text { terminal }\end{array}$ & $\begin{array}{l}\text { Mensurar o tempo em que a carga } \\
\text { pode ficar armazenada no } \\
\text { terminal sem custos para o cliente }\end{array}$ & $\begin{array}{l}\text { O tempo de armazenagem sem } \\
\text { custos é uma vantagem } \\
\text { competitiva }\end{array}$ \\
\hline $\begin{array}{l}\text { Tempo médio } \\
\text { de operação }\end{array}$ & $\begin{array}{l}\text { Estimar o tempo médio em que } \\
\text { um navio será } \\
\text { carregado/descarregado }\end{array}$ & $\begin{array}{c}\text { Prever o horário de saída do } \\
\text { navio }\end{array}$ \\
\hline $\begin{array}{l}\text { Tempo médio } \\
\text { do percurso de } \\
\text { carga e descarga } \\
\text { do caminhão }\end{array}$ & $\begin{array}{l}\text { Mensurar o tempo que o } \\
\text { contêiner leva para sair do } \\
\text { costado até a pilha }\end{array}$ & $\begin{array}{l}\text { Possibilita estimar a quantidade } \\
\text { de caminhões necessária }\end{array}$ \\
\hline $\begin{array}{l}\text { Tempo ocioso } \\
\text { dos } \\
\text { equipamentos }\end{array}$ & Estimar o tempo ocioso & Tempo ocioso resulta em custos \\
\hline $\begin{array}{c}\text { Tempo que o } \\
\text { caminhão } \\
\text { externo } \\
\text { permanece no } \\
\text { terminal }\end{array}$ & $\begin{array}{l}\text { Mensurar o tempo em que a carga } \\
\text { é retirada do caminhão, } \\
\text { empilhada no pátio e o caminhão } \\
\text { sai do terminal. }\end{array}$ & $\begin{array}{c}\text { Possibilita visualizar a } \\
\text { rotatividade de caminhões e o } \\
\text { tempo para o empilhamento }\end{array}$ \\
\hline $\begin{array}{l}\text { Tempo que o } \\
\text { navio ficou } \\
\text { atracado }\end{array}$ & $\begin{array}{l}\text { Mensurar o tempo total em que o } \\
\text { navio ficou atracado no terminal }\end{array}$ & $\begin{array}{l}\text { O tempo de atracação não pode } \\
\text { ser maior do que a janela do } \\
\text { navio }\end{array}$ \\
\hline $\begin{array}{l}\text { Utilização do } \\
\text { portão de } \\
\text { entrada (gate) }\end{array}$ & $\begin{array}{l}\text { Identificar a quantidade de } \\
\text { caminhões externos entraram no } \\
\text { terminal }\end{array}$ & $\begin{array}{c}\text { Possibilita identificar a } \\
\text { quantidade de carga para } \\
\text { exportação e estimar o trânsito } \\
\text { no terminal }\end{array}$ \\
\hline $\begin{array}{l}\text { Velocidade de } \\
\text { operação dos } \\
\text { equipamentos }\end{array}$ & $\begin{array}{l}\text { Identificar a performance do } \\
\text { equipamento }\end{array}$ & $\begin{array}{l}\text { Equipamentos mais rápidos } \\
\text { resultam em melhor } \\
\text { desempenho }\end{array}$ \\
\hline $\begin{array}{l}\text { Volume e TEUs } \\
\text { movimentados }\end{array}$ & $\begin{array}{c}\text { Mensurar a movimentação do } \\
\text { terminal }\end{array}$ & $\begin{array}{c}\text { Maior volume e TEUs } \\
\text { movimentados representam } \\
\text { maior lucro ao terminal }\end{array}$ \\
\hline
\end{tabular}


Fonte: Elaboração própria (2015).

O Quadro 2 resume a revisão sistemática apresentando o resultado da pesquisa. No cenário dos terminais de contêineres, este quadro pode ser utilizado como referência para a gestão por indicadores, pontuando cada indicador com o objetivo de obter tal mensuração e sua justificativa.

Contudo, não se pode afirmar que esses sejam os únicos indicadores dos terminais de contêineres. Por integrar um cenário complexo, cada terminal possui especificidades que necessitam ser mensuradas por indicadores, logo, o resultado da pesquisa serve como um direcionador geral, agregando os indicadores listados no estado da arte.

O desenvolvimento do terminal de contêineres é um fator essencial para qualquer país que deseje obter sucesso no comércio internacional. Os portos são a porta de entrada para acessar os parceiros comerciais globais e o transporte marítimo é um dos meios mais eficientes de longa distância. Um dos principais desafios para os portos de contêineres de hoje é a melhoria das instalações, para atender ao aumento das dimensões dos navios, e as pressões correspondentes à velocidade de movimentação de carga (UNCTAD, 2015), que podem ser alcançadas com a gestão direcionada aos indicadores.

\section{CONCLUSÃO}

Cumprindo os objetivos propostos, o artigo apresentou o desenvolvimento da pesquisa iniciando-se com a estruturação das etapas da revisão sistemática, sendo realizada em 3 bases de dados e mantendo-se o rigor do método proposto, a fim de garantir a qualidade dos dados coletados e manter o foco na solução do problema de pesquisa. Após esta etapa, foram levantados os indicadores descritos por seus respectivos autores; com um total de 17 trabalhos relacionados ao tema, pontuaram-se todos indicadores abordados por cada autor separadamente.

Buscando determinar os indicadores operacionais mais relevantes dos terminais de contêineres, todos os dados obtidos no estado-da-arte foram revisados a fim de eliminar as repetições, obtendo-se assim um total de 40 indicadores operacionais dos terminais de contêineres.

Vale ressaltar que a identificação desses indicadores poderá ser utilizada como direcionador para medir a eficiência operacional do terminal, identificação de benchmark, e implantação de uma gestão por indicadores estruturada; apesar de apresentar de forma clara os indicadores do estado da arte, não se pode concluir que estes sejam os únicos que devam ser considerados; cada terminal possui especificidades operacionais que devem ser mensuradas por indicadores que podem não constar no resultado apresentado pelo artigo.

Como continuidade da pesquisa, pode-se identificar, dentre os 40 indicadores operacionais apresentados no estado da arte, quais deles são mais relevantes. Por meio de um instrumento de pesquisa aplicado a gestores ou especialistas de operações dos diversos terminais de contêineres, com o suporte do método de hierarquização Analytic Hierarchy Process (AHP), poder-se-ia obter um ranking dos indicadores segundo seu grau de importância. 


\title{
Operational indicators of container terminals
}

\begin{abstract}
The performance indicators are crucial in strategic management and processes of an organization; it can be measured in different ways and in different levels of complexity. Container terminals, which are responsible for the connection between maritime and land transport modalities, are a central element in any transport system, considering several operational variables in order to obtain better operational performances. With this, the research seeks to determine whether there is a set of standard operating indicators to measure the efficiency of container terminals. The purpose of this article is to determine the most relevant operational indicators of container terminals, through a systematic review conducted in the databases Emerald, Scopus and Periódicos Capes, in the period between 2010 and 2016, presenting the benchmarks. The result of the research was a set of 40 operational indicators obtained; these can be used as drivers for management by indicators with operational focus on container terminals.
\end{abstract}

KEYWORDS: Indicador; Container Terminal; Operational. 


\section{REFERÊNCIAS}

ABRATEC (2015) Estatísticas. Disponível em: <http://www.abratecterminais.org.br/estatisticas> Acesso em: 10/02/2015.

AL-ERAQI, A.; MUSTAFA, A.; KHADER, A. An extended DEA windows analysis: Middle East and East African seaports. Journal of Economic Studies, v. 37, n. 2, p. 208-218, 2010. crossref

BALDASSARRA, A.; IMPASTATO, S.; RICCI, S. Intermodal terminal simulation for operations management. European Transport, v. 46, p. 86-99, 2010.

CAGGIANI, L. et al. A fuzzy data meta training system for ranking hub container terminals. European Transport, v. 51, c. 4, p. 1-16, 2012.

CARTENI, A.; LUCA, S. Tactical and strategic planning for a container terminal: Modelling issues within a discrete event simulation approach. Simulation Modelling Practice and Theory, v. 21, p. 123-145, 2012. crossref

EMERALD (2015) About Emerald. Disponível em: < http://www.emeraldgrouppublishing.com/about/index.htm> Acesso em 23/02/2015.

FENG, M.; MANGAN, J.; LALWANI, C. Comparing port performance: Western European versus Eastern Asian ports. International Journal of Physical Distribution \& Logistics Management, v. 42, n. 5, p. 490-512, 2012. crossref

GOHR, C. et al. Um método para a revisão sistemática da literatura em pesquisas de Engenharia de Produção. Anais do XXXIII Encontro Nacional de Engenharia de Produção. Salvador: Anais do XXXIII ENEGEP, 2013.

HAUSER, J.; KATZ, G. Metrics: You Are What You Measure! European Management Journal, v. 16, n. 5, p. 517-528, 1998. crossref

HUANG, W. et al. A Research on the Improvement Strategy on the Operation performance of Container Terminal. Journal of the Eastern Asia Society for Transportation Studies, v. 9, p. 2256-2271, 2010.

JIANG, J. et al. Port connectivity study: An analysis framework from container liner shipping network perspective. Transportation Research Part E, v. 73, p. 4764, 2015. crossref 
JÚNIOR, R. Hierarquização dos Indicadores de Desempenho da Qualidade Aplicada aos Terminais Portuários de Movimentação de Contêineres.

Dissertação de Mestrado, Programa de Mestrado em Engenharia de Transportes no Instituto Militar de Engenharia. Rio de Janeiro, Rio de Janeiro, Fevereiro de 2008.

KAPLAN, R.; NORTON, D. Putting the Balanced Scorecard to Work. Harvard Business Review, v. 71, n. 5, p. 134-147, 1993.

KAPLAN, R.; NORTON, D. The Balanced Scorecard - Measures that drive performance. Harvard Business Review, v. 5, n. 3, p. 71-79, 1992.

LAM, J.; SONG, D. Seaport network performance measurement in the context of global freight supply chains. Polish Maritime Research, v. 20, p. 47-54, 2013. crossref

LARGEN, P.; SHARYPOVA, K. Intermodal connectivity as a port performance indicator. Research in Transportation Business \& Management, v. 8, p. 97-102, 2013. crossref

LOH, H.; THAI, V. Management of disruptions by seaports: preliminary findings. Asia Pacific Journal of Marketing and Logistics, v. 27, n. 1, p. 146-162, 2015. crossref

MARTINS, P.; LAUGENI, F. Administração da Produção. 2ā. ed. São Paulo: Editora Saraiva, 2005.

MAUBOUSSIN, M. The True Measures of Success. Most Companies Use The Wrong Performance Metrics. Don't Be One Of Them. Harvard Business Review, v. 90, n. 10, p. 4-10, 2012.

MERK, O.; DANG, T. (2012) Efficiency of world ports in container and bulk cargo. Disponível em: <http://dx.doi.org/10.1787/5k92vgw39zs2-en> Acesso em: 19/02/2015.

NIEDRITIS, A.; NIEDRITE, L.; KOZMINA, N. Performance measurement framework with formal indicator definitions. Perspectives in Business Informatics Research, v. 90, p. $44-58,2011$. cross ref

NOORAMIN, A.; AHOUEI, V.; SAYAREH, J. A Six Sigma framework for marine container terminals. International Journal of Lean Six Sigma, v. 2, n. 3, p. 241253,2011 . crossref 
PERIÓDICOS CAPES (2015) Missão e objetivos. Disponível em:

$<$ http://www.periodicos.capes.gov.br/index.php?option=com_pcontent\&view=p content\&alias=missao-objetivos\&Itemid=126> Acesso em 23/02/2015.

PORTOS DO BRASIL (2014) Sistema Portuário Nacional. Disponível em: <http://www.portosdobrasil.gov.br/assuntos-1/sistema-portuario-nacional> Acesso em: 12/02/2015.

PUN, K.; NURSE, A. Adopting quality management principles to revitalise the facilities maintenance practices at a port: A study in Trinidad and Tobago. The Asian Journal on Quality, v. 11, n. 3, p. 197-209, 2010. crossref

RASHIDI, H.; TSANG, E. Novel constraints satisfaction models for optimization problems in container terminals. Applied Mathematical Modelling, v. 37, p. 3601-3634, 2013. crossref

RIOS, C.; SOUSA, R. Cluster analysis of the competitiveness of container ports in Brazil. Transportation Research Part A, v. 69, p. 423-431, 2014. crossref

SCOPUS (2015) An eye on global research. Disponível em:

<http://www.elsevier.com/online-tools/scopus> Acesso em 23/02/2015.

SHAN, J.; YU, M.; LEE, C. Na empirical investigation of the seaport's economic impact: Evidence from major ports in China. Transportation Research Part E, v. 69, p. 41-53, 2014. crossref

TALLEY, M.; NG, M. Maritime transport chain choice by carriers, port and shippers. Int. J. Production Economics, v. 142, p. 311-316, 2013. crossref

TAPIA, R. et al. Proposición y Evaluación de Indicadores de Movimiento de Carga para el puerto de Mar Del Plata. Espacios, v. 35, n. 11, p. 9-21, 2014.

TOVAR, B.; HERNÁNDEZ, R.; RODRÍGUEZ-DÉNIZ, H. Container port competitiveness and connectivity: The Canary Islands main ports case. Transport Policy, v. 38, p. 40-51, 2015. crossref

TRANFIELD, D.; DEYER, D.; SMART, P. Towards a Methodology for Developing Evidence-Informed Management Knowledge by Means of Systematic Review. British Journal of Management, v. 14, n. 3, p. 207-222, 2013. crossref 
UNCTAD (2015) Review of Maritime Transport 2014. Disponível em: <http://unctad.org/en/pages/PublicationWebflyer.aspx?publicationid=1068> Acesso em 15/02/2015.

YEO, G.; ROE, M.; DINWOODIE, J. Measuring the competitiveness of container ports: logisticians' perspectives. European Journal of Marketing, v. 45, n.3, p. 455-470, 2011. crossref

Recebido: 25 jan. 2017

Aprovado: 12 set. 2017

DOI: 10.3895/gi.v13n2.5356

Como citar:

RODRIGUES, T. A.; SELEME, R. Indicadores operacionais dos terminais de contêineres. R. Gest. Industr. Ponta Grossa, v. 13, n. 2, p. 160-181, jun./ago. 2017. Disponível em: <https://periodicos.utfpr.edu.br/rgi> Acesso em: XXX.

Correspondência:

Thiago de Almeida Rodrigues

Comendador Correa Junior, 410-casa 9, Joao Gualberto, Paranaguá, Paraná, Brasil

Direito autoral: Este artigo está licenciado sob os termos da Licença Creative Commons-Atribuição 4.0

Internacional. 